\title{
Q-Switched Neodymium-Doped Yttrium Aluminum Garnet Laser Therapy for Pigmented Skin Lesions: Efficacy and Safety
}

\author{
Karn $D,{ }^{1} \mathrm{KC} S,{ }^{2}$ Amatya $A,{ }^{1}$ Razouria EA,${ }^{1}$ Timalsina $M,{ }^{1}$ Suwal $A^{1}$
}

${ }^{1}$ Department of Dermatology and Venereology, Dhulikhel Hospital, Kathmandu University Hospital

2Department of Emergency, Dhulikhel Hospital, Kathmandu University Hospital

\section{Corresponding author:}

Dharmendra Karn

Department of Dermatology and Venereology

Dhulikhel Hospital, Kathmandu University Hospital

Kavre, Nepal

email: dddkarn@gmail.com

\section{Citation}

Karn D, KC S, Amatya A, Razouria EA, Timalsina M, Suwal A. Q-Switched Neodymium-Doped Yttrium Aluminum Garnet Laser Therapy for Pigmented Skin Lesions: Efficacy and Safety. Kathmandu Univ Med J 2012;38(2):46-50.

\begin{abstract}
Background

Nepalese population with Fitzpatrick skin types III-V has high prevalence of pigmentary disorders and it is a growing cosmetic concern. Q-Switched NeodymiumDoped Yttrium Aluminum Garnet (QS Nd-YAG) laser is an efficacious tool in the treatment of pigment disorders.
\end{abstract}

\section{Objective}

To highlight the efficacy and safety profile of various pigment disorders.

\section{Methods}

A prospective study done in Dhulikhel Hospital, Kathmandu University Hospital from January 2009 to January 2011. Patients undergoing laser for pigmented skin lesions were followed for response and safety profile. We included total 270 patients in the study with various disorders especially nevus, tattoos and melasma. Settings were repeated at 3-4 weeks interval and response was evaluated on clinical basis. Efficacy was then evaluated according to various parameters.

\section{Results}

For nevus, total 840 treatment sessions had been performed with an average of 6.88 sessions (range 3-11). Nd: YAG laser was very efficacious in removal of blue and black colored tattoos with an average of 7.9 and 9.5 sessions respectively. However, red mixed with blue and or green tattoos were relatively resistant to treatment and required average 10.33 treatment sessions. Melasma and freckles both responded to the therapy but recurrence rate was high.

\section{Conclusion}

Our results indicate that QS Nd: YAG laser is an effective modality for pigment disorders among Nepalese population. Nevus and melasma respond well but recurrence rate of melasma is high. Blue tattoos respond well while mixed colored tattoos are quite resistant to Nd: YAG laser alone. Transient pain and temporary hyperpigmentation are common side effects.

\section{KEY WORDS}

Laser, melasma, nevus, tattoo.

\section{INTRODUCTION}

Skin disorders relating pigmentation encompass a range of problems from inherited to acquired disorders. Skin color is generally determined by the number of chromophores namely melanin, hemoglobin and carotenoids. ${ }^{1}$ Pigmentation especially on face may result significant emotional and psychological distress. Various modalities were used in the past with varying results. Since the advent of modified lasers by Anderson and Parrish in 1983, which works on the principle of selective photothermolysis, laser is today an inseparable part of dermatology practice..$^{1,2}$
Freckles, cafe'-au-lait macules, melasma and lentigines are the epidermal disorders while nevus of Ota and acquired conditions as tattoos, post inflammatory hyperpigmentation are common dermal pigmentary disorders presenting to us. Various lasers are used for the treatment of pigment disorders with varying efficacy and side effects. But in comparison, Nd: YAG laser at 1064 nanometer emits light with larger wavelength and therefore have relatively deeper dermal penetration and thus has quicker effect. ${ }^{1}$ Hence, $1064 \mathrm{~nm}$ is used for dermal pigmentation and 532 
$\mathrm{nm}$ is used for epidermal pigmentation. Limited data are available for the efficacy of laser therapy in our population.

Hence this article highlights the efficacy and safety profile of the Q-switched Nd: YAG laser for various pigmentary disorders among Nepalese population.

\section{METHODS}

This is a prospective, longitudinal and analytical study conducted in Dhulikhel Hospital Kathmandu University Hospital over a period of two years (from January 2009 to January 2011). We included total 270 patients in our study treated for various pigment disorders mainly nevus, melasma and tattoos.

Priming was done initially for all lesions using hydroquinone or topical tretinoin and sunscreen (for facial lesions) for four weeks because retinizing the skin improves wound healing and decreases post-laser hyperpigmentation. ${ }^{6}$ We treated all patients using Q-switched Nd: YAG laser with 10 nanosecond pulse duration repeated at interval of 3-4 weeks. $532 \mathrm{~nm}$ was applied for epidermal lesions while dermal lesions were treated with $1064 \mathrm{~nm}$. Digital photographs were taken and were compared at subsequent visits for improvement or any probable side effects. Patients missed during the treatment sessions and patients treated with two or more lasers or having chemical peel for facial lesions were excluded from the study.

Patients were asked for self satisfaction of laser therapy after the final session. ${ }^{20}$ Excellent corresponded to 75 $100 \%$ clearance, good to $50-74 \%$ clearance, fair to $25-49 \%$ clearance, and poor to $0 \%-24 \%$ clearance. Treatment was considered effective when there was $50 \%$ to complete clearance of lesions.

\section{RESULTS}

Table 1. Various cases treated with Q-switched Nd: YAG laser.

\begin{tabular}{|lll|}
\hline SI. No. & Pigmentary Disorder & No. of Cases \\
\hline 1 & Nevus & 122 \\
\hline 2 & Tattoos & 62 \\
\hline 3 & Melasma & 46 \\
\hline 4 & Post Inflammatory Hyperpigmentation & 23 \\
\hline 5 & Scar & 8 \\
\hline 6 & Freckles & 7 \\
\hline 7 & Dermatosis Papulosa Nigra and skin tags & 2 \\
\hline
\end{tabular}

We performed total 840 sessions for various nevi especially Nevus of Ota and Becker's nevus among 122 patients (79 female and 43 male). Figure 1 represents the improvement of nevus following laser therapy according to age group. Proper improvements were seen after fourth session and average treatment session was calculated to be 6.88 (range 3-11 sessions). Patient satisfaction score for nevus was: excellent $16.4 \%$, good $67.2 \%$, fair $13.9 \%$ and poor $2.5 \%$.

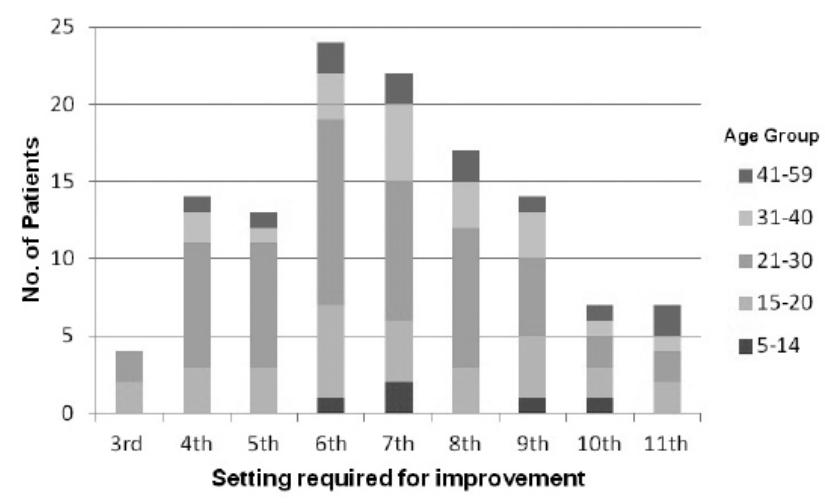

Figure 1. Number of treatment sessions required for clearance of nevus according to age group.

62 patients (47 male and 15 female) were treated for tattoo removal with total 549 settings. Tattoos were basically of three colors: blue $(n=31)$, green $(n=19)$ and red tattoo mixed with blue and or green color $(n=12)$. Figure 2 shows the efficacy of laser for clearance of various tattoos.

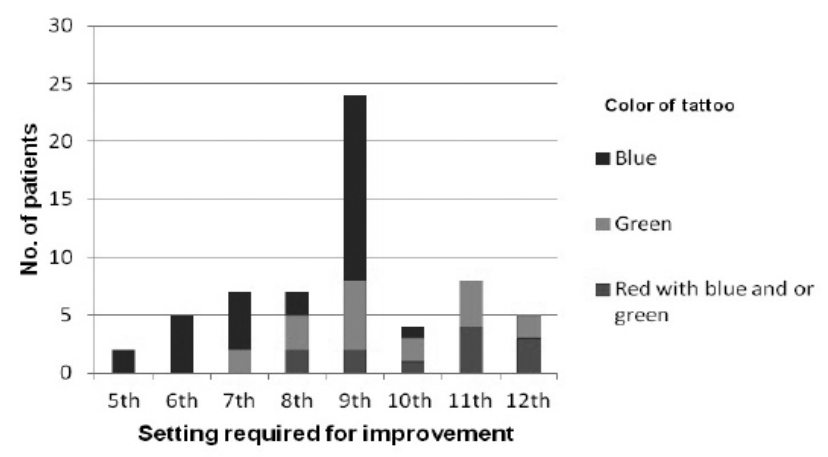

Figure 2. Number of treatment sessions required for clearance of various colored tattoos.

For blue colored tattoos, improvement began to appear after fifth session. Total 245 sessions were required for them with an average of 7.9 (range 5-10). Q-switched Nd: YAG laser was most effective in removal of blue colored tattoos. For green colored tattoos we performed total 180 sessions with an average of 9.5 (range 7-12). Red mixed with blue and or green tattoos were somewhat resistant to $\mathrm{Nd}$ : YAG laser treatment only. Total 124 sessions were required with average 10.33 (range 8-12). For resistant tattoos, combination of QS Nd: YAG laser with fractional Erbium YAG-2940 laser was found to be effective. Figure 3 shows the patient satisfaction score for different colored tattoos.

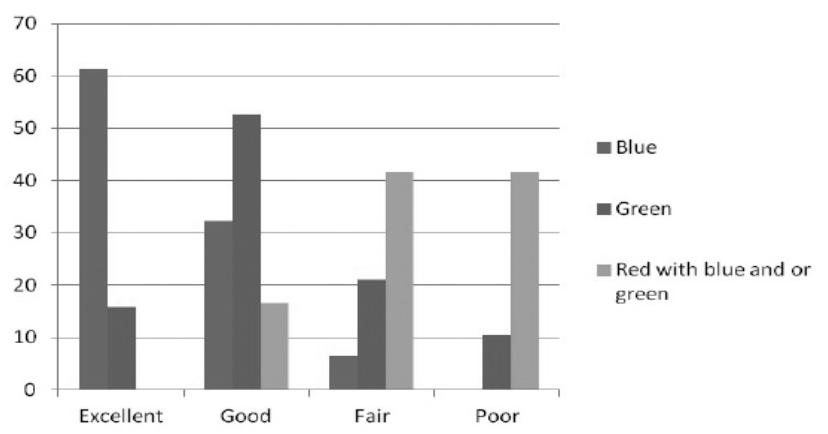

Figure 3. shows the patient satisfaction score for different colored tattoos. 


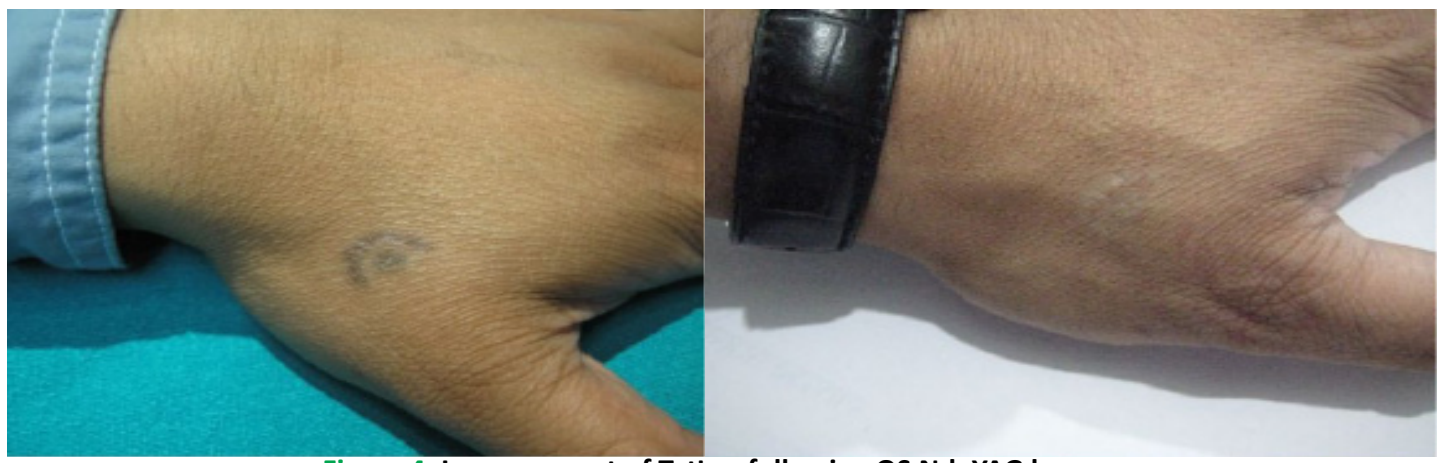

Figure 4. Improvement of Tattoo following QS Nd: YAG laser.

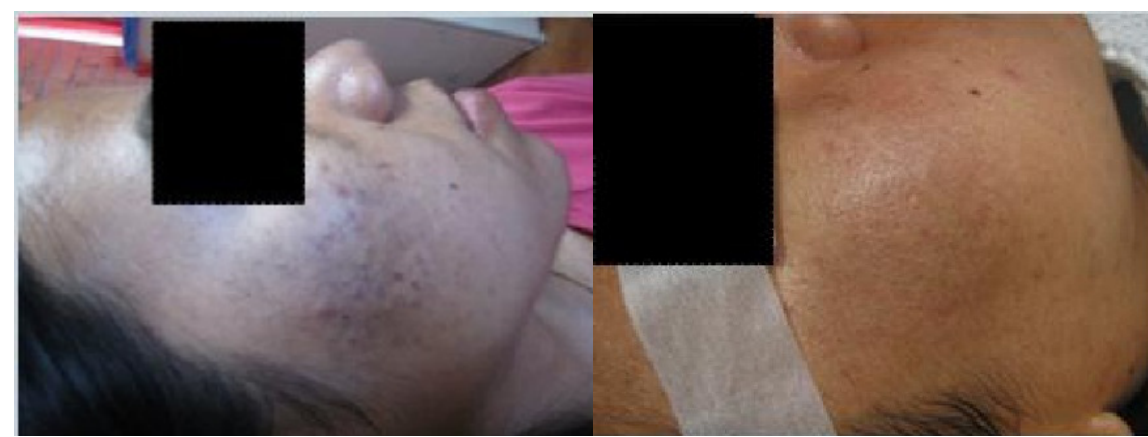

Figure 5. Improvement of Nevus following QS Nd: YAG laser.

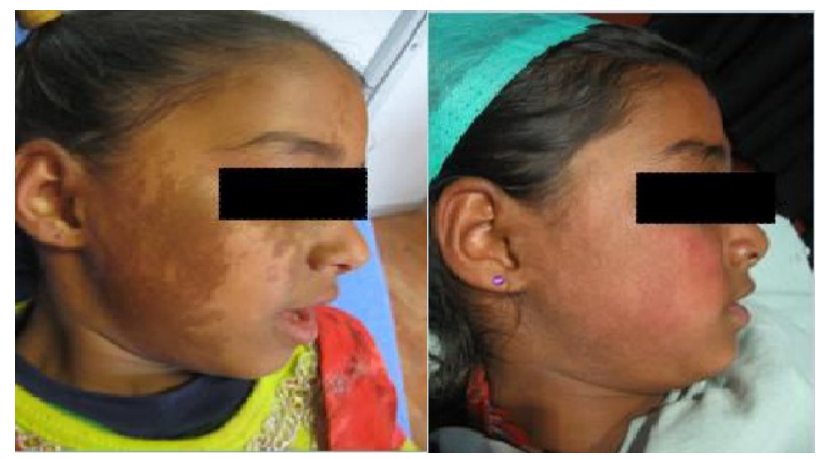

Figure 6. Improvement of PIH following QS Nd: YAG laser.

Melasma and freckles both responded well to treatment. 28 of 46 patients $(60.8 \%)$ had near clearing of the lesion. However, recurrence was a common problem. We could not estimate the exact recurrence rate because we lost many patients during follow up. Patient satisfaction score on melasma was: excellent: $4.3 \%$, good: $58.7 \%$, fair: $26 \%$ and poor: $10.9 \%$.

Regarding safety profile pain during the therapy and transient hyperpigmentation lasting for maximum 7 days was a common side effect. We encountered temporary erythema in 26 patients

\section{DISCUSSION}

Treatment of selective pigmented skin lesions is possible nowadays using various laser systems. Permanent remedy and low complications have today created a high demand of laser surgery. As melanin has a broad absorption spectrum, Q-switched Nd: YAG, ruby and alexandrite lasers have all been evaluated for the treatment of such lesions. Q-switched lasers create a very short pulse (5-100 nanoseconds) together with an extremely high power. Also, $\mathrm{Nd}$ : YAG laser at $1064 \mathrm{~nm}$ has deep dermal penetration and does not target epidermal melanin much hence; post treatment hyperpigmentation is not that common. ${ }^{3}$

In Kavre district, Pigmented skin lesion is the most frequent problem (32.56\%) seen in dermatology practice and there are limited literatures on the treatment of pigmented skin lesions among Nepalese population. ${ }^{5}$

\section{Nevus:}

A retrospective analysis was done by $\mathrm{Chan} \mathrm{HH}$ et al. among 129 patients treated with either $\mathrm{Q}$ switched alexandrite or $\mathrm{Q}$ switched $\mathrm{Nd}$ : YAG, or both lasers. ${ }^{7}$ Complete clearing versus $50 \%$ lightening was seen in $0 \% / 25.9 \%$ of the $Q$ switched alexandrite treated cases, $1.9 \% / 38.1 \%$ of the $Q$ switched Nd: YAG-treated cases and $8.3 \% / 72.9 \%$ of cases treated with both, respectively. 13 (5.2\%) patients with $90 \%$ clearance had recurrence after four years follow up. Textural changes, scarring and dyspigmentation were common among patients treated with the $\mathrm{Q}$ switched 
alexandrite or both lasers. Q switched Nd: YAG laser is thus effective than the $Q$ switched alexandrite laser and also offers minimal untoward effects.

$\mathrm{Nd}$ : YAG laser at $1064 \mathrm{~nm}$ has shown good response in clearance of pigmentation of nevus of Ota without obvious side effect with multiple treatments. ${ }^{8,9}$ In a prospective trial, acquired nevus of Ota was treated with $Q$ switched $\mathrm{Nd}$ : YAG laser (8-10 J/cm2, 2-4 $\mathrm{mm}$ spot sizes) and found to have $100 \%$ clearance in 68 of 70 patients after two to five treatment sessions. Transient hyperpigmentation was seen in $50 \%$ patients, without scarring or textural changes, and no recurrence was seen at four years follow-up. ${ }^{9}$ Similar study done by Polnikorn $\mathrm{N}$ et al showed good to excellent results in $50 \%(33 / 66)$ patients who received more than two treatment sessions with Nd: YAG laser. ${ }^{10}$ Study done in population similar to ours for various pigmented lesions took one to six sessions for epidermal lesions, four to six sessions for dermal lesions, and two to three sessions for mixed lesions. ${ }^{11}$ Thirty four patients (56.7\%) showed excellent response, seven patients (11.7\%) showed good response, nine patients (15\%) showed fair response and 10 (16.6\%) showed poor response. These results correspond to our result which showed good response to treatment after fourth treatment session. Patients had an average of 6.88 (range 3-11) setting for clearance of lesion and total patient satisfaction score was $83.6 \%$.

\section{Melasma:}

Melasma is far more common in women and in dark skinned individuals. Exposure to Ultra violet rays remains one of the major etiologies in both melasma and freckles. ${ }^{4,6}$ Lasers are used nowadays as a resurfacing procedure for melanin degradation. Nd : YAG laser is the frequently used modality for treatment of melasma/freckles. Q switched ruby laser was once used for this but severe post inflammatory hyperpigmentation in some patients concluded it to be ineffective for melasma treatment. ${ }^{12}$ Large spot size and low energy mode QS Nd: YAG laser is a new recommended method for melasma. ${ }^{13}$ Dermal melasma was treated along with topical preparations, and after ten weeks treatment $66.7 \%$ of patients achieved more than $50 \%$ of clearance. ${ }^{17}$ Two cases (5.7\%) had recurrence two months after the last treatment.

Zhou Xi et. al. evaluated 50 patients of melasma and calculated Melasma Area and Severity Index (MASI). ${ }^{6}$ The result was $70 \%$ of patients had more than a $50 \%$ decrease in their MASI score, and $10 \%$ had $100 \%$ clearance.Sixty four percent patients had recurrence on three month follow up. These findings correspond to our finding where $60.8 \%$ patients had near clearing of the lesion and patient satisfaction score was $63 \%$. In our study, efficacy of laser therapy was found to be good irrespective of Fitzpatrick skin type of the patient, age, sex or pathologic type of melasma. However, high recurrence rate was a disappointing conclusion.

Though there is a very good response of $\mathrm{Q}$ switched $\mathrm{Nd}$ : YAG laser for the treatment of melasma and freckles, recurrence remains a major drawback. Adjunctive measures to maintain this response needs to be explored in the near future.

\section{Tattoo:}

Tattoos have been used since ancient times to accentuate beauty but during the course of time many people regret having a tattoo. ${ }^{1}$ In the U.S. $17 \%$ population with tattoos consider tattoo removal. ${ }^{18} \mathrm{QS} \mathrm{Nd}$ : YAG is the therapy of choice for tattoos on Fitzpatrick skin type IV to VI patients, as the $1064 \mathrm{~nm}$ wavelength penetrates deeper and is minimally absorbed by epidermal melanin. ${ }^{14,15}$ Thus it is used to remove blue and black ink tattoos in darker skin types $(1064 \mathrm{~nm})$ or red pigment $(532 \mathrm{~nm})$. For resistant tattoos, combination therapy of two or more lasers is found to be helpful. Weiss ET. et. al. combined ablative fractional laser with $Q$ switched laser and their results showed that with combination therapy tattoo removal appears to increase tattoo clearance, eliminate blistering, shorten recovery, and diminish treatment-induced hypopigmentation. ${ }^{19}$ This finding was similar to in our experience where we have combined QS Nd: YAG laser with fractional Erbium YAG laser.

Q-switched ruby, Q-switched Nd: YAG (1064 and 532nm) and $\mathrm{Q}$-switched alexandrite are the lasers currently used for tattoo removal. Table 1 represents the comparison of various laser systems for various colored tattoos. ${ }^{15}$

Longer wavelength $\mathrm{Q}$ switched Nd: YAG laser produces better results in tattoo removal among patients with dark complexion with respect to fairer population. Also comparative studies recommend that the $\mathrm{Q}$ switched $\mathrm{Nd}$ : YAG laser has lower incidence of pigmentary changes and scarring, as compared to the QS ruby laser for tattoo removal. ${ }^{16}$

Our results for tattoos are similar to above findings as blue and black colored tattoos require comparatively less setting than red or green tattoos with Qs Nd: YAG laser. Hence, we can conclude that Nd: YAG laser is a very good treatment modality for treatment of blue/black colored tattoos in Fitzpatrick skin types III-V.

\section{CONCLUSION}

Q-switched Nd: YAG laser has a good response in treatment of pigmented skin lesions among Nepalese population. Nevus, freckles, melasma, blue and green colored tattoos show very good outcome. However, Recurrence rate of Melasma/freckles is high and red mixed with blue and or green tattoos are relatively resistant to $\mathrm{Nd}$ : YAG laser alone.

\section{REFERENCES}

1. Burns T, Breathnach S, Cox N, Griffiths C. Rook's textbook of dermatology. 8th ed. Wiley-Blackwell: 2010; 58.1-58.3.

2. Anderson RR, Parry JA. Selective photothermolysis precise microsurgery by selective absorption of pulsed radiation. Science 1983; 220:524-7. 
3. Burns T, Breathnach S, Cox N, Griffiths C. Rook's textbook of dermatology. 8th ed. Wiley-Blackwell: 2010;78.1-78.5.

4. Cameron KR, Richard EF. The treatment of melasma with fractional photothermolysis: a pilot study. Dermatol Surg 2005; 31:1645-50.

5. Karn D, Khatri R, Timalsina M. Prevalence of skin diseases in Kavre district, Nepal. Nepal J Dermatol Venereol Leperol.2010; 10:07-10.

6. $\mathrm{XI}$ Z, Gold MH, Ahong LU, Ying L. Efficacy and Safety of Q-Switched 1,064-nm Neodymium-Doped Yttrium Aluminum Garnet Laser Treatment of Melasma. Dermatol Surg.2011; 37:962-70.

7. Chan HH, Leung RSC, Ying S-Y, Lai C-F, Kono T, Chua JK et.al. A retrospective analysis of complications in the treatment of nevus of Ota with the Q-switched alexandrite andQ-switched Nd:YAG lasers. Dermatol Surg.2000; 26:1000-06.

8. Chan $\mathrm{HH}$, Ying SY, Ho WS, Kono T, King WW. An in vivo trial comparing the clinical efficacy and complications of Q-switched $755 \mathrm{~nm}$ alexandrite and Q-switched $1064 \mathrm{~nm} \mathrm{Nd:YAG} \mathrm{lasers} \mathrm{in} \mathrm{the} \mathrm{treatment}$ of nevus of Ota. Dermatol Surg.2000; 26:919-22.

9. Kunachak S, Leelaudomlipi P. Q-switched Nd:YAG laser treatment for acquired bilateral nevus of Ota-like maculae: a long-term follow-up. Lasers Surg Med.2000; 26:476-9.

10. Polnikorn N, Tanrattanakorn S, Goldberg DJ. Treatment of Hori's nevus with the Q-switched Nd:YAG laser. Dermatol Surg.2000; 26:477-80.

11. Salem A, Harras ME, Ramadan A, Gamil H, Rahman AA, Said KE. Use of the Q-switched Nd:YAG laser for the treatment of pigmentary disorders in Egyptians 2010; 12:92-100.
12. Taylor CR, Anderson RR. Ineffective treatment of refractory melasma and postinflammatory hyperpigmentation by Q-switched ruby laser. Dermatol Surg Oncol.1994; 20:592-7.

13. Wattanakrai P, Mornchan R, Eimpunth S. Low-fluence Q-switched neodymium-doped yttrium aluminum garnet $(1,064 \mathrm{~nm})$ laser for the treatment of facial melasma in Asians. Dermatol Surg.2010; 36:7687.

14. Green JB, Metelitsa AI. Optimizing outcomes of laser tattoo removal. Skin Therapy Lett. 2011; 16(10):1-3.

15. Mariwalla K, Dover JS. The use of lasers for decorative tattoo removal. Skin Therapy Lett. 2006; 11(5):8-11.

16. Werner S, Drosner M, Raulin C. Tattoo removal Q-switched ruby laser $(694 \mathrm{~nm})$ and theQ-switched Nd:YAG laser (532 and $1064 \mathrm{~nm})$. A retrospective study. Hautarzt.1999;50:174-180.

17. Polnikorn N. Treatment of refractory melasma with the MedLite C6 Q-switched Nd:YAG laser and alpha arbutin: a prospective study. Cosmet Laser Ther 2010; 12:126-31.

18. Laumann $A E$, Derick AJ. Tattoos and body piercings in the United States: a national data set. J Am Acad Dermatol. 2006; 55(3):413-21.

19. Weiss ET, Geronemus RG. Combining fractional resurfacing and Q-switched ruby laser for tattoo removal. Dermatol Surg.2011; 37(1):97-9.

20. Zhou XI, Michael GH, Lu Z, Ying L. Efficacy and Safety of Q-Switched 1,064-nm Neodymium-Doped Yttrium Aluminum Garnet Laser Treatment of Melasma. Dermatol Surg. 2011; 37(7):962-70. 